\title{
Two new $\alpha$-class milbemycin metabolites from mutant Streptomyces avermitilis NEAU1069-3
}

\author{
Lian-jie Li ${ }^{1}$, Dan Zhou ${ }^{1}$, An-liang Chen ${ }^{2}$, Jun Huang ${ }^{3}$, Hui Zhang ${ }^{3}$, Ji-dong Wang ${ }^{2,3}$ and Wen-sheng Xiang ${ }^{1}$
}

The Journal of Antibiotics (2015) 68, 354-356; doi:10.1038/ja.2014.159; published online 26 November 2014

\begin{abstract}
Microbial metabolites attract increasing attention as potential pesticides owing to their potential bioactivity and low toxicity to non-target animals and humans. ${ }^{1,2}$ Several microbial metabolites, such as avermectins, milbemycins, have been commercialized and considered to be the most widely used drugs in animal health and agriculture. ${ }^{3}$ During the course of the screening program for new natural pesticides and antiparasitic veterinary drugs, two novel macrocyclic lactones, three milbemycins and six new doramectin congeners have been isolated from Streptomyces avermitilis NEAU1069.4-7 To screen for more bioactive compounds, a mutant $S$. avermitilis NEAU1069-3 was obtained by UV treatment and two new doramectin analogs were isolated from its fermentation broth. ${ }^{8}$ In further work to explore the chemical diversity of the constituent of $S$. avermitilis NEAU1069-3, two new $\alpha$-class milbemycins, 23, 24-didehydro-13 $\alpha$-hydroxy milbemycin $A_{3}(1)$ and 24, 30-didehydro-13 $\alpha$-hydroxy milbemycin $A_{3}(2)$ were isolated from the broth of $S$. avermitilis NEAU1069-3. Herein, we describe the fermentation, isolation, structural elucidation and insecticidal activity of the two new $\alpha$-class milbemycins.
\end{abstract}

The culture and fermentation of $S$. avermitilis NEAU1069-3 were conducted according to the procedure as described previously. ${ }^{6}$ Thirty liters of broth from $300 \times 100 \mathrm{ml}$ fermentations was filtered. The resulting cake was washed with water, and both filtrate and wash were discarded. Methanol (101) was used to extract the washed cake. The $\mathrm{MeOH}$ extract was evaporated under reduced pressure to 21 at $45^{\circ} \mathrm{C}$ and the resulting concentrate was extracted three times using an equal volume of EtOAc. The combined EtOAc phase was concentrated under reduced pressure to yield $26 \mathrm{~g}$ of oily substances. The residual oily substance was chromatographed on silica gel (Qingdao Haiyang Chemical Group, Qingdao, China; 100-200 mesh) and eluted with a petroleum ether-acetone mixture $(100: 0-50: 50, \mathrm{v} / \mathrm{v})$. The fractions eluted with petroleum-acetone mixture $(85: 15, \mathrm{v} / \mathrm{v})$ were combined and evaporated to obtain fraction I and the fractions eluted with the petroleum ether-acetone mixture $(80: 20, \mathrm{v} / \mathrm{v})$ were pooled and concentrated to give fraction II. The fraction I was subjected to Sephadex LH-20 (GE Healthcare, Glies, UK) column eluting with
$\mathrm{MeOH}$ to give subfraction I. The semi-preparative HPLC (Agilent 1100, Zorbax SB-C18, $5 \mu \mathrm{m}, 250 \times 9.4 \mathrm{~mm}$ i.d.; Agilent, Palo Alto, CA, USA) was applied to obtain pure compounds. The eluates were monitored using a photodiode array detector at $254 \mathrm{~nm}$, and the flow rates were $1.5 \mathrm{ml} \mathrm{min}^{-1}$ at room temperature. The subfraction I was further separated by semi-preparative HPLC using a solvent containing a $\mathrm{CH}_{3} \mathrm{OH}-\mathrm{CH}_{3} \mathrm{CN}-\mathrm{H}_{2} \mathrm{O}$ mixture $(72: 7: 21$, v/v/v) to obtain compound $1\left(t_{\mathrm{R}} 17.3 \mathrm{~min}, 12 \mathrm{mg}\right)$ and the fraction II was subjected to Sephadex LH-20 column eluting with $\mathrm{MeOH}$ to give subfraction II and the subfraction II was purified by the semi-preparative HPLC using a solvent containing a $\mathrm{CH}_{3} \mathrm{OH}-\mathrm{CH}_{3} \mathrm{CN}-\mathrm{H}_{2} \mathrm{O}$ mixture (69:24:7, $\mathrm{v} / \mathrm{v} / \mathrm{v})$ to obtain compound $2\left(t_{\mathrm{R}} 30.1 \mathrm{~min}, 8 \mathrm{mg}\right)$.

Compound 1 was isolated as colorless oil with $[\alpha]_{D}^{25} 43.3$ (c 0.03 , $\mathrm{EtOH})$ and $\mathrm{UV}(\mathrm{EtOH}) \lambda_{\max } \mathrm{nm}(\log \varepsilon): 245$ (4.01). The positive HRESIMS showed a pseudo molecular ion at $m / z 565.2759(\mathrm{M}+\mathrm{Na})^{+}$, corresponding to the molecular formula $\mathrm{C}_{31} \mathrm{H}_{42} \mathrm{O}_{8}$ that required 11 degrees of unsaturation. The IR spectrum of 1 showed absorption bands assignable to the hydroxyl group $\left(3400 \mathrm{~cm}^{-1}\right)$ and carbonyl group $\left(1710 \mathrm{~cm}^{-1}\right)$. The ${ }^{1} \mathrm{H}$ NMR spectrum of 1 showed two doublet aliphatic methyl signals at $\delta_{\mathrm{H}} 1.15(3 \mathrm{H}, \mathrm{d}, J=7.0 \mathrm{~Hz}), 1.24$ $(3 \mathrm{H}, \mathrm{d}, J=6.7 \mathrm{~Hz})$, three olefinic methyl signals at $\delta_{\mathrm{H}} 1.52(3 \mathrm{H}, \mathrm{br} \mathrm{s})$, $1.61\left(3 \mathrm{H}\right.$, br s), $1.79\left(3 \mathrm{H}\right.$, br s) and one trans-double bond at $\delta_{\mathrm{H}} 5.73$ $(1 \mathrm{H}, \mathrm{dd}, J=14.9,9.8 \mathrm{~Hz})$ and $5.93(1 \mathrm{H}, \mathrm{dd}, J=14.9,11.2 \mathrm{~Hz})$. Inspection of the ${ }^{13} \mathrm{C}$ NMR (DEPT) and HMQC spectra revealed the existence of an ester carbonyl at $\delta_{\mathrm{C}} 171.7(\mathrm{~s})$, a ketal at $\delta_{\mathrm{C}} 96.7$ (s), six oxygenated methines at $\delta_{\mathrm{C}} 80.7$ (d), 76.7 (d), 68.5 (d), 68.1 (d), $67.7(\mathrm{~d})$ and $67.0(\mathrm{~d})$, two aliphatic methines at $\delta_{\mathrm{C}} 45.8(\mathrm{~d}), 40.2(\mathrm{~d})$, one oxygenated quaternary carbon at $\delta_{\mathrm{C}} 80.4(\mathrm{~s})$, one oxygenated methylene at $\delta_{\mathrm{C}} 67.4(\mathrm{t})$, five methyls at $\delta_{\mathrm{C}} 18.9(\mathrm{q}), 18.9(\mathrm{q}), 18.4(\mathrm{q})$, 18.3 (q) and 13.7 (q) in addition to four aliphatic methylenes and ten $s p^{2}$ carbons. Comparison of the ${ }^{1} \mathrm{H}$ NMR data (Table 1) of 1 with those of the milbemycin $A_{3}$ suggested that 1 was similar to milbemycin $\mathrm{A}_{3}{ }^{9}$. The differences between $\mathbf{1}$ and milbemycin $\mathrm{A}_{3}$ were that 1 contained a double bond at C-23 and C-24 and a hydroxy group at C-13. The ${ }^{1} \mathrm{H}-{ }^{1} \mathrm{H}$ COSY correlation of $\delta_{\mathrm{H}} 4.19$ and $\delta_{\mathrm{H}} 2.59$, and the

${ }^{1}$ Life Science and Biotechnology Research Center, School of Life Science, Northeast Agricultural University, Harbin, China; ${ }^{2}$ Provincial Joint Engineering Laboratory of Biopesticide Preparation, Zhejiang Agricultural and Forestry University, Lin'an, China and ${ }^{3}$ Department of New Drug Screening, Zhejiang Hisun Pharmaceutical Co., Ltd., Taizhou, China Correspondence: Dr J-D Wang, Department of New Drug Screening, Zhejiang Hisun Pharmaceutical Co., Ltd., Taizhou 318000, China.

E-mail: jdwang@hisunpharm.com

or Professor W-S Xiang, Life Science and Biotechnology Research Center, School of Life Science, Northeast Agricultural University, Harbin 150030, China. E-mail: xiangwensheng@neau.edu.cn

Received 21 July 2014; revised 14 October 2014; accepted 27 October 2014; published online 26 November 2014 
Table $1{ }^{1} \mathrm{H}$ and ${ }^{13} \mathrm{C}$ NMR data of compounds 1 and 2

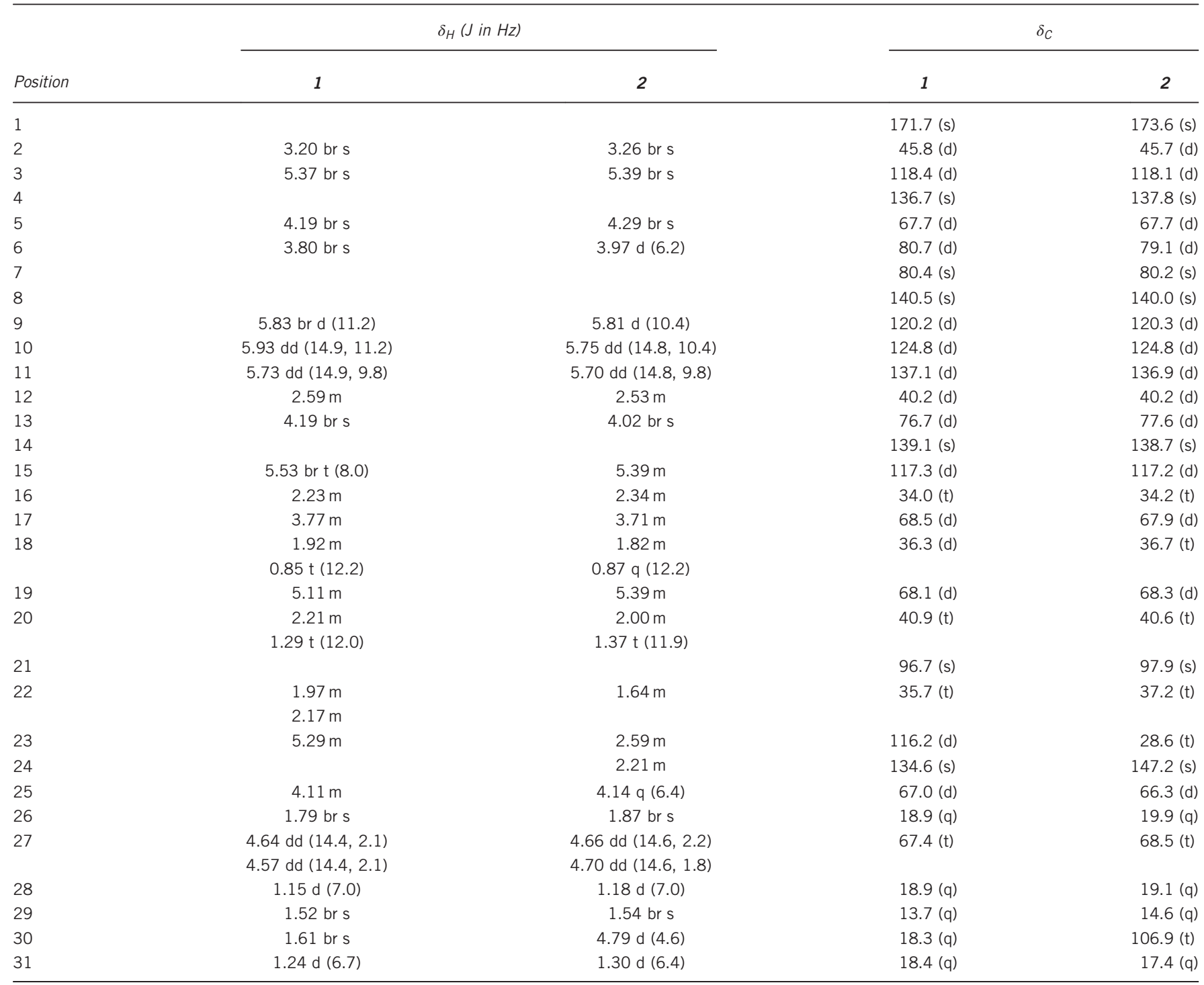

observed HMBC correlation from $\mathrm{H}_{3}-30$ to $\delta_{\mathrm{C}} 116.2$ (C-23), $\delta_{\mathrm{C}} 135.6$ $(\mathrm{C}-24)$ and $\delta_{\mathrm{C}} 62.0(\mathrm{C}-25)$ and from $\mathrm{H}_{3}-28$ and $\mathrm{H}_{3}-29$ to $\delta_{\mathrm{C}} 76.7$ (C-13) further confirmed the structural assignment of $\mathbf{1}$. As a result, the gross structure of $\mathbf{1}$ was established as shown in Figure 1. The small coupling constant of $\mathrm{H}-13(1 \mathrm{H}$, br s) compared with that of doramectin ${ }^{10}$ indicated that the 13-hydroxy was $\alpha$-oriented. The other relative stereochemistry of $\mathbf{1}$ was assigned by analogy with milbemycin $\mathrm{A}_{3}$.

Compound 2 was isolated as colorless oil with $[\alpha]_{D}^{25} 73.3$ (c 0.03 , $\mathrm{EtOH})$ and UV (EtOH) $\lambda_{\max } \mathrm{nm}(\log \varepsilon): 245$ (4.29). It's molecular formula was determined to be $\mathrm{C}_{31} \mathrm{H}_{42} \mathrm{O}_{8}$ on the basis of HRESIMS at $m / z 565.2743[\mathrm{M}+\mathrm{Na}]^{+}$(cald 565.2772 for $\mathrm{C}_{31} \mathrm{H}_{42} \mathrm{NaO}_{8}$ ), indicating 11 degrees of unsaturation. The IR spectrum of 2 showed absorption bands assignable to the hydroxyl group $\left(3400 \mathrm{~cm}^{-1}\right)$ and carbonyl group $\left(1730 \mathrm{~cm}^{-1}\right)$. The ${ }^{1} \mathrm{H}$ NMR spectrum of 2 showed one transdouble bond at $\delta_{\mathrm{H}} 5.75(1 \mathrm{H}, \mathrm{dd}, J=14.8,10.4 \mathrm{~Hz})$ and $5.70(1 \mathrm{H}, \mathrm{dd}$, $J=14.8,9.8 \mathrm{~Hz})$, two olefinic methyls at $\delta_{\mathrm{H}} 1.54(3 \mathrm{H}, \mathrm{br} \mathrm{s}), 1.87(3 \mathrm{H}$, br s), two aliphatic doublet methyls at $\delta_{\mathrm{H}} 1.18(3 \mathrm{H}, \mathrm{d}, J=7.0 \mathrm{~Hz})$ and
$1.30(3 \mathrm{H}, \mathrm{d}, J=6.4 \mathrm{~Hz})$. The ${ }^{13} \mathrm{C}$ NMR and DEPT spectra of 2 displayed an ester carbonyl at $\delta_{\mathrm{C}} 173.6(\mathrm{~s})$, a ketal carbon at $\delta_{\mathrm{C}} 97.9$ (s), four $s p^{2}$ quaternary carbons, five $s p^{2}$ methines, one $s p^{2}$ methylene, one oxygenated quaternary carbon, six oxygenated methines, one oxygenated methylene in addition to two aliphatic methines, five aliphatic methylenes and four methyls. Detailed analysis of the ${ }^{1} \mathrm{H}$ and ${ }^{13} \mathrm{C}$ NMR data of $\mathbf{2}$ (Table 1 ) suggested that $\mathbf{2}$ has a same scaffold as $\mathbf{1}$, except the $\Delta^{23,24}$ olefin in 1 was disappeared and a $\Delta^{24,30}$ olefin was present in 2 . The downfield ${ }^{13} \mathrm{C}$ NMR chemical shift at C-30 $\left(\delta_{\mathrm{C}}\right.$ 106.9) and the $\mathrm{HMBC}$ correlations (Figure 1) from $\delta_{\mathrm{H}} 4.79$ to $\delta_{\mathrm{C}} 28.6$ $(\mathrm{t}, \mathrm{C}-23), 147.2(\mathrm{~s}, \mathrm{C}-24)$ and $66.3(\mathrm{~d}, \mathrm{C}-25)$ and from $\delta_{\mathrm{H}} 1.30(3 \mathrm{H}, \mathrm{d})$ to 147.2 (s, C-24) and 66.3 (d, C-25) further confirmed the structural assignment of $\mathbf{2}$ as shown in Figure 1. The relative stereochemistry of $\mathbf{2}$ was assigned by analogy with $\mathbf{1}$.

The insecticidal activities of compounds 1 and $\mathbf{2}$ against Brevicoryne brassicae (L.) were tested by the leaf dip method and the insecticidal capacities of the two compounds were compared with milbemycin $\mathrm{A}_{3} / \mathrm{A}_{4}$. In this technique, the aphids were collected from insecticide- 


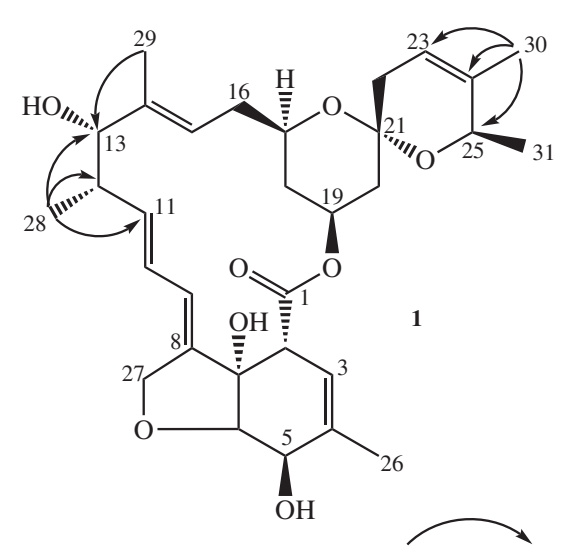

Figure 1 Structures and key HMBC correlations of compounds 1 and 2.

Table 2 Insecticidal activities of compounds 1 and 2 against Brevicoryne brassicae

\begin{tabular}{lcccc}
\hline Compound & $Y$ & $\begin{array}{c}1 \mathrm{C}_{50} \\
\left(\mathrm{mg}^{-1}\right)\end{array}$ & $\begin{array}{c}\text { Coefficient } \\
\text { correlation }\end{array}$ & $\begin{array}{c}\text { 95\% Confidence } \\
\text { interval }\end{array}$ \\
\hline $\mathbf{1}$ & $5.4063+1.3447 \mathrm{X}$ & 0.4987 & 0.9928 & $0.41-0.61$ \\
$\mathbf{2}$ & $5.3108+1.2708 \mathrm{X}$ & 0.5694 & 0.9972 & $0.46-0.71$ \\
Milbemycins & $5.0878+1.4836 \mathrm{X}$ & 0.8726 & 0.9945 & $0.7-1.09$ \\
$\mathrm{~A}_{3} / \mathrm{A}_{4}{ }^{a}$ & & & & \\
\hline aMilbemycins $\mathrm{A}_{3}$ and $\mathrm{A}_{4}$ mixtures, 30:70 (in volume) & & \\
\hline
\end{tabular}

free flowering-Chinese cabbage and reared at room temperature. Serial dilutions (five concentrations) of each compound were prepared in distilled water for use in the bioassays. Leaf discs with a diameter of $\sim 35 \mathrm{~mm}$ were prepared from cabbage leaves and dipped for $30 \mathrm{~s}$ in various concentrations of each test material. Leaf discs dipped only in distilled water served as controls. The dried leaf discs were then transferred to Petri dishes and 80-90 aphids were released in each dish. The mortality was recorded after $24 \mathrm{~h}$. The mortality of the treated compound was corrected using the control mortality and the corrected data were used to calculate $\mathrm{LC}_{50}$ values. The bioassays were performed simultaneously on three replicates for each concentration. The bioassay results (Table 2) demonstrated that compounds $\mathbf{1}$ and $\mathbf{2}$ have good aphidicidial activities and would be a potential insecticide

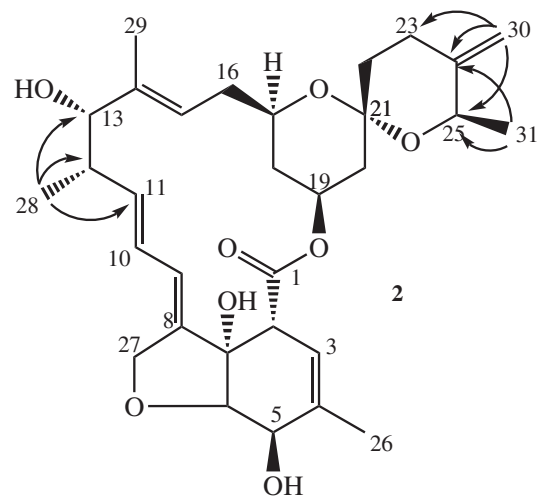

HMBC

\section{ACKNOWLEDGEMENTS}

This research work was financially supported by the Special Program for the Science and Technology Plan of Zhejiang Province of China, under Grant No. 2012C03006-2, the National Key Project for Basic Research (2010CB126102) and the National Natural Science Foundation of China (30771427 and 31000884).

1 Tanaka, Y. \& Omura, S. Agroactive compounds of microbial origin. Annu. Rev. Microbiol. 47, 57-87 (1993).

2 Saxena, S. \& Pandey, A. K. Microbial metabolites as eco-friendly agrochemicals for the next millennium. Appl. Microbiol. Biotechnol. 55, 395-403 (2001).

3 Carter, G. T. et al. LL-F28249 antibiotic complex: a new family of antiparasitic macrocyclic lactones. Isolation, characterization and structures of LL-F28249 alpha, beta, gamma, lambda. J. Antibiot. 41, 519-529 (1988).

4 Wang, M. et al. New $\beta$-class milbemycin compound from Streptomyces avermitilis NEAU1069: fermentation, isolation and structure elucidation. J. Antibiot. 62, 587-591 (2009).

5 Wang, X. J. et al. Isolation and identfication of novel macrocyclic lactones from Streptomyces avermitilis NEAU1069 with acaricidal and nematocidal activity. J. Agric. Food Chem. 58, 2710-2714 (2010).

6 Wang, X. J. et al. Two new doramectin analogs from Streptomyces avermitilis NEAU1069: fermentation, isolation and structure elucidation. J. Antibiot. 64 591-594 (2011).

7 Xiang, W. S. et al. Four new doramectin congeners with acaricidal and insecticidal activity from Streptomyces avermitilis NEAU1069. Chem. Biodiversity 8 , 2117-2125 (2011).

$8 \mathrm{Li}$, J. S. et al. New doramectin analogs from mutant Streptomyces avermitilis NEAU1069-3. J. Antibiot. 67, 187-189 (2014).

9 Ley, S. V., Madinb, A. \& Moncka, N. J. T. Total synthesis of the spiroketal macrolide (+) milbemycin $\alpha_{1}$. Tetrahedron Lett. 34, 7479-7482 (1993).

10 Dutton, C. J. et al. Structure of doramectin. J. Chem. Soc. Perkin Trans. 2, 403-408 (1995). 